\title{
The value of antibodies against mutated citrullinated vimentin in juvenile idiopathic arthritis
}

\author{
D Guseinova1 ${ }^{1}$, A Lazareva*1, R Shantere ${ }^{2}$, D Berzinja ${ }^{2}$, O Rasnachs ${ }^{1}$ and \\ V Stanevicha ${ }^{1}$
}

Address: ${ }^{1}$ Riga Stradinsh University, Riga, Latvia and ${ }^{2}$ Children's Clinical University Hospital, Riga, Latvia

* Corresponding author

from $15^{\text {th }}$ Paediatric Rheumatology European Society (PreS) Congress

London, UK. 14-17 September 2008

Published: 15 September 2008

Pediatric Rheumatology 2008, 6(Suppl I):P67 doi:10.I I86/I546-0096-6-SI-P67

This abstract is available from: http://www.ped-rheum.com/content/6/SI/P67

(c) 2008 Guseinova et al; licensee BioMed Central Ltd.

\section{Background}

Antibodies against cyclic citrullinated peptid (anti-CCP) and mutated citrullinated vimentin (anti-MCV) have been extensively studied as an early diagnostic and prognostic markers in rheumatoid arthritis (RA), however there is little data available on the role of anti-MCV in Juvenile idiopathic arthritis (JIA).

\section{Objectives}

To detect significance of anti-MCV in children with JIA.

\section{Materials and methods}

We analysed 41 patients with newly diagnosed JIA (25 RF negative polyarthritis, 10 oligoarthritis, 5 undifferentiated and 1 psoriatic arthritis). To evaluate disease activity, clinical (disease type, number of active and inactive joints) and laboratory (CRP, ESR, TNF alfa, ANA titer, HLA B 27 antigen) data were recorded. The level of anti-MCV in the sera of JIA patients and 21 controls (healthy chidren with no family history of any rheumatological disease) was measured using ELISA method (Orgenetic Diagnostica, GbmH, Germany). For statistical analysis we used T test and Mann-Whitney test.

\section{Results}

Although mean anti-MCV level in the JIA group was highier $(3.73 \mathrm{U} / \mathrm{ml}$, range $2-10 \mathrm{U} / \mathrm{ml})$, then in the control group $(3.14 \mathrm{U} / \mathrm{ml}$, range $2-9 \mathrm{U} / \mathrm{ml})$, these results are not statistically singificant $(\mathrm{p}>0.05)$. Evaluating disease activity, we found a positive correaltion of anti-MCV with CRP $(\mathrm{p}<0.05)$ and serum amiloid A (SAA) $(\mathrm{p}<0.01)$ level. SAA has a positive predictive value for anti-MCV.

\section{Conclusion}

Anti-MCV can't serve as an early JIA diagnosting marker. There is a direct correlation between anti-MCV level and acute inflammatory markers and anti-MCV can be used as a disease activity marker.

\section{References}

I. Egerer K, et al.: A New Powerful Marker for the Diagnosis and Prognosis of Rheumatoid Arthritis - Anti-CVM (Anti-Citrullinated Vimentin Mutated) Antibodies [abstract]. Arthritis Rheum 2005, 52:SII8.

2. Hassfeld WG, Vinje O, König K, et al.: Autoantibodies to mutated citrullinated vimentin in juvenile rheumatoid arthritis. Ann Rheum Dis 2006, 65(Suppl II):439. 